\title{
Representation of Vertical Atmospheric Structures by Radio Occultation Observations in the Upper Troposphere and Lower Stratosphere: Comparison to High-Resolution Radiosonde Profiles
}

\author{
Zhen Zeng, Sergey Sokolovskiy, William S. Schreiner, And Doug Hunt \\ COSMIC Program Office, University Corporation for Atmospheric Research, Boulder, Colorado
}

(Manuscript received 22 June 2018, in final form 5 February 2019)

\begin{abstract}
Global positioning system (GPS) radio occultation (RO) is capable of retrieving vertical profiles of atmospheric parameters with high resolution $(<100 \mathrm{~m})$, which can be achieved in spherically symmetric atmosphere. Horizontal inhomogeneity of real atmosphere results in representativeness errors of retrieved profiles. In most cases these errors increase with a decrease of vertical scales of atmospheric structures and may not allow one to fully utilize the physical resolution of RO. Also, GPS RO-retrieved profiles are affected by observational noise of different types, which, in turn, affect the representation of small-scale atmospheric structures. This study investigates the effective resolution and optimal smoothing of GPS RO-retrieved temperature profiles using high-pass filtering and cross correlation with collocated high-resolution radiosondes. The effective resolution is a trade-off between representation of real atmospheric structures and suppression of observational noise, which varies for different latitudes $\left(15^{\circ} \mathrm{S}-75^{\circ} \mathrm{N}\right)$ and altitudes $(10-27 \mathrm{~km})$. Our results indicate that at low latitudes the effective vertical resolution is about $0.2 \mathrm{~km}$ near the tropical tropopause layer and about $0.5 \mathrm{~km}$ in the lower stratosphere. The best resolution of $0.1 \mathrm{~km}$ is at the cold-point tropical tropopause. The effective resolutions at the midlatitudes are slightly worse than at low latitudes, varying from $\sim 0.2$ to $0.6 \mathrm{~km}$. At high latitudes, the effective resolutions change notably with altitude from $\sim 0.2 \mathrm{~km}$ at $10-15 \mathrm{~km}$ to $\sim 1.4 \mathrm{~km}$ at $22-27 \mathrm{~km}$. Our results suggest that the atmospheric inhomogeneity plays an important role in the representation of the vertical atmospheric structures by RO measurements.
\end{abstract}

\section{Introduction}

In conventional radio occultation (RO) inversion algorithms, retrieval of atmospheric parameters from the $\mathrm{RO}$-measured signal phases is done in the geometrical optics (GO) approximation, where the signal paths are treated as rays which are bent according to Snell's law. In a spherically symmetric atmosphere, the total influence of the atmosphere on the RO signal can be described by bending angle of the ray with a given impact parameter. The ray bending angle and impact parameter can be derived from the measured Doppler-shifted frequency of the transmitted signal at the receiver by removing the Doppler shift caused by the motions of transmitter and receiver satellites. The profile of atmospheric refractivity can be then calculated through the Abel transform (Kursinski et al. 1997). The classic GO method assumes the spherically symmetric atmosphere and single-path propagation which makes it straightforward and simple

Corresponding author: Zhen Zeng, zzeng@ucar.edu for implementation. In case of multipath propagation (which commonly happens in the lower troposphere due to complicated refractivity structures) disentangling multiple rays, summed with their phases and amplitudes in RO signal, is a difficult task in GO approximation. The wave optics (WO) methods use the complex RO signal (phase and amplitude), by transforming it from time (coordinate) to impact parameter representation thus effectively resolving multiple rays under the assumption of spherical symmetry. Several WO methods were developed, including back propagation (BP) (Gorbunov et al. 1996), sliding spectrum (SS) (Sokolovskiy 2001), canonical transform (CT) (Gorbunov 2002), full spectrum inversion (FSI) (Jensen et al. 2003), and phase matching (PM) (Jensen et al. 2004). Though different WO methods are based on different assumptions about satellite orbits and result in different computational costs, they tend to have similar retrieval accuracy and resolution. The methods based on fast Fourier transform, such as CT and FSI, are most computationally efficient. On the other hand, PM is the most accurate, 
because it uses least assumptions and approximations. Typically, both GO and WO are combined in processing a RO profile; GO is applied for upper levels (e.g., stratosphere), while WO is more often applied for lower levels (e.g., troposphere).

An important feature associated with GO and WO approaches is the vertical resolution of RO retrievals. The vertical resolution of GO retrievals is limited by diffraction effects in the atmosphere and free space and is commonly characterized by the first Fresnel zone at ray tangent point. For L-band global positioning system (GPS) signals and a typical orbit altitude of low-Earthorbiting (LEO) satellites $\sim 750 \mathrm{~km}$, the vertical scale of the first Fresnel zone is about $1.5 \mathrm{~km}$ in the stratosphere and $0.5 \mathrm{~km}$ in the lower troposphere (Kursinski et al. 1997). On the other hand, the WO methods can achieve sub-Fresnel vertical resolution by accounting for diffraction effects in a free space (Gorbunov et al. 2004). Previous studies estimated the vertical resolution of the BP method to be about $100 \mathrm{~m}$ (Mortensen et al. 1999) and the CT and FSI methods about $60 \mathrm{~m}$ (Gorbunov et al. 2004). However, this resolution can only be fully utilized for a spherically symmetric atmosphere. The horizontal inhomogeneity of a real atmosphere results in representativeness errors of retrieved vertical profiles [a detailed theoretical investigation of these errors was done by Ahmad and Tyler (1998)]. In most (but not all) cases these errors increase with the decrease of vertical scales of atmospheric structures, because the horizontalto-vertical aspect ratio, required for locally spherical symmetry, increases. A rule of thumb for considering an atmospheric structure locally spherically symmetric is $\Delta L>2 \sqrt{2 R \Delta z}$, where $\Delta L$ and $\Delta z$ are horizontal and vertical scales of the structure, and $R$ is Earth's radius (Kursinski et al. 1997). These representativeness errors may not allow full utilization of the physical resolution of RO. In addition, GPS RO data and retrieved profiles are affected by observational noise of different types (ionospheric residuals, thermal noise, unmodeled clock effects), which may impede resolution of the vertical small-scale atmospheric structures. Observational noise may be different for different occultations but, on average, its magnitude in bending angle does not change significantly with height, while the neutral atmospheric bending angle decreases approximately exponentially and therefore is overshadowed by the noise above some height. In retrieved temperature, the effect of noise increases about exponentially up to the height where bending angle is affected by optimization (Kuo et al. 2004) while the error of the first guess dominates above that height. Commonly this height is above $30 \mathrm{~km}$ and does not affect the results of this study.
Ionospheric residuals that remain after ionospheric correction are one of the main error sources of GPS RO in the stratosphere. The standard linear combination of L1 and L2 bending angle (ionospheric correction) at the same impact height removes the first-order ionospheric contribution from total bending angle (Vorobev and Krasilnikova 1994). However, higher-order ionospheric effects related to L1 and L2 ray path separation and small-scale ionospheric structures remain in the "ionospheric free" bending angle [the effects related to higher-order terms in the Appleton-Hartree equation are negligible according to Syndergaard (2000)]. While the systematic effect (bias) related to L1 and L2 ray path separation in the ionosphere can be modeled and approximately corrected (Healy and Culverwell 2015), mitigation of the effect of small-scale ionospheric irregularities is a more difficult problem (Sokolovskiy et al. 2014).

The representativeness and observational errors pose an important question about vertical resolution and optimal smoothing of the GPS RO-retrieved profiles. The smoothing should be based on a trade-off between representation of the vertical atmospheric structures at maximum possible resolution and suppression of the variations of retrieved profiles uncorrelated with the atmospheric structures. The resulting smoothing scale corresponds to an effective vertical resolution of the GPS RO which, generally, is different from the physical resolution and may be different in different height intervals. In this study, the effective vertical resolution of RO-retrieved temperature profiles is estimated in the altitude range of $10-27 \mathrm{~km}$. Below $10 \mathrm{~km}$, the inverse problem of deriving temperature from refractivity becomes underdetermined due to the moisture; while above $27 \mathrm{~km}$ the observational noise (which includes the measurement noise and the ionospheric residuals) overshadows the natural atmospheric small-scale variations with vertical wavelength as short as $0.5 \mathrm{~km}$ (Tsuda et al. 2011). Furthermore, the horizontal inhomogeneity of real atmosphere (e.g., gravity wave activities) and observational noise (e.g., ionospheric residuals) can be also different for different latitudes. Therefore, it is useful to investigate the altitudinal and latitudinal variations of the effective vertical resolutions and understand their relations to different error sources.

In a previous study, Tsuda et al. (2011) analyzed the vertical spectra of temperature profiles retrieved by GO and FSI from the Constellation Observing System for Meteorology, Ionosphere and Climate (COSMIC) GPS RO measurements up to $30-\mathrm{km}$ altitude and compared them to the spectrum obtained from high-resolution radiosondes. The GPS RO spectra obtained by GO had noticeably lower spectral density than those obtained by FSI due to the lower resolution of GO. The GPS RO 
spectra obtained by FSI were in good agreement with the radiosonde spectrum and consistent with the theoretical slope for saturated gravity waves (GW) up to some wavenumber. At larger wavenumbers, the spectra saturate indicating the existence of a noise floor. A cutoff wavenumber was used to deduce the resolution of GPS RO. Tsuda et al. (2011) arrived at a conclusion that the vertical resolution of the FSI is about $100-200 \mathrm{~m}$ in the lower stratosphere.

Because the shape of the spectrum of ionospheric residuals may be different from that of white noise (Yeh and Liu 1982), this potentially may affect the estimation of the resolution by the cutoff wavenumber. In other words, variations of the GPS RO-retrieved profiles with wavenumbers smaller than the cutoff may still, to a large extent, represent ionospheric residuals. In this study, to estimate the effective vertical resolution, we use direct comparison of GPS RO-retrieved temperature profiles to collocated radiosondes, without the use of the shape of the spectrum. We note that GPS RO-retrieved temperature profiles were compared to radiosonde profiles in a number of previous studies (Kuo et al. 2005; He et al. 2009; Sun et al. 2010; Ho et al. 2017). In this study, we use high-resolution radiosondes and apply tight collocation criteria both in space and time. In addition to direct comparison of temperature profiles, we calculate cross-correlation coefficients of the high-pass filtered temperature profiles from GPS RO and radiosondes for different filter windows. The window at which the crosscorrelation coefficient reduces below some threshold value is used for the estimation of the effective vertical resolution. The results obtained with this approach do not depend on the shape of the spectrum of GPS RO observational noise, but they do depend on both GPS RO and radiosonde observational noises. As it follows from Tsuda et al. (2011), radiosonde spectrum retains the slope close to that for GW at wavenumbers larger than the GPS RO cutoff. This suggests that radiosondes may have smaller observational noise than GPS RO in the stratosphere. Still, because our results are affected by two uncorrelated observational noises, they may be treated as an upper estimate of RO vertical resolution, while the results obtained from the shape of GPS RO spectrum (Tsuda et al. 2011) may be treated as a lower estimate for the reason explained above.

In section 2, we describe the RO data processing algorithm modified specifically for this study and the radiosonde data sources. In section 3, we compare GPS $\mathrm{RO}$ and radiosonde temperature profiles and estimate the effective vertical resolution by their high-pass filtering and cross correlation in $5-\mathrm{km}$ altitudinal subintervals covering range from 10 to $27 \mathrm{~km}$. Additionally, we estimate the resolution at the tropical tropopause by direct comparison of the cold-point tropopause temperatures and heights from GPS RO and radiosondes. Section 4 concludes the study. The appendix describes the filter used in this study.

\section{Datasets}

\section{a. High-resolution RO data}

First, we briefly introduce the standard RO neutral atmospheric data processing used in the UCAR COSMIC Data Analysis and Archive Center (CDAAC). The excess phase and signal-to-noise ratio (SNR) of an RO signal (available in the "atmPhs" files) are inverted into atmospheric bending angle, refractivity, dry temperature, and pressure profiles (available in the "atmPrf" files) under the assumption of a spherically symmetric and dry atmosphere (Kuo et al. 2004; Schreiner et al. 2011). At altitudes above $20 \mathrm{~km}, \mathrm{~L} 1$, and L2 excess phases are smoothed using Savitzky-Golay filter with a constant window in time that is consistent with the physical GO resolution (Fresnel's zone) (this is described in more details in the appendix). The GO method is applied to calculate both L1 and L2 bending angles, $\alpha_{1}$ and $\alpha_{2}$, from the smoothed excess phase derivatives. The ionosphere-free bending angle is then calculated as $\alpha_{1}+C_{2}\left\langle\alpha_{1}-\alpha_{2}\right\rangle$, where $C_{2}=f_{2}^{2} /\left(f_{1}^{2}-f_{2}^{2}\right)$, $f_{1}$ and $f_{2}$ are GPS L1 and L2 carrier frequencies, 1.57542 and $1.2276 \mathrm{GHz}$, respectively, and \langle\rangle denotes additional smoothing of $\alpha_{1}-\alpha_{2}$ using an optimal filter window to balance the unfiltered L2 noise and the uncorrected small-scale ionospheric effects (Sokolovskiy et al. 2009). This window is determined individually for each occultation in the interval between 1 and 3 times the size of the L1 window. Below $20 \mathrm{~km}$, the L1 bending angle is derived from the raw complex signal (phase and amplitude) using the PM method (Jensen et al. 2004). The highresolution WO bending angle is smoothed to $0.2-1.0 \mathrm{~km}$ according to the altitude (see Table 1). The WO ionosphere-free bending angle is obtained by the correction of WO-processed L1 bending angle by the extrapolated GO-processed $\alpha_{1}-\alpha_{2}$ from above (Zeng et al. 2016). Finally, GO and WO bending angles are merged into one profile at the transition height of $20 \mathrm{~km}$. Refractivity is derived from an optimized bending angle by Abel inversion, and pressure and temperature are derived from refractivity under the assumptions of dry air and hydrostatic equilibrium (Kuo et al. 2004). Some documents explaining $\mathrm{RO}$ data processing at CDAAC can be found online (https://cdaac-www.cosmic.ucar.redu/ cdaac/doc/overview.html).

In addition to using the standard reprocessed COSMIC RO atmospheric profiles from atmPrf files 
TABLE 1. Parameters used in the standard and high-resolution RO data processing. The asterisk indicates that the filter window width for GO L1 is explained in the appendix.

\begin{tabular}{lcc}
\hline \hline & Standard RO retrievals (V13) & $\begin{array}{c}\text { High-resolution RO } \\
\text { retrievals (V16) }\end{array}$ \\
\hline Transition height between GO and WO & $20 \mathrm{~km}$ & $30 \mathrm{~km}$ \\
Height for extrapolation of the ionospheric correlation & $20 \mathrm{~km}$ & $20 \mathrm{~km}$ \\
Filter window for WO L1 bending angle & $1 \mathrm{~km}(10<h<20 \mathrm{~km}), 450 \mathrm{~m}(7<h<$ & $100 \mathrm{~m}$ \\
Filter window for GO L1-L2 bending angle & $10 \mathrm{~km}), 200 \mathrm{~m}(h<7 \mathrm{~km})$ & As in V13 \\
& Dynamically determined between 1 and 3 & times the window width for GO L1* \\
\hline
\end{tabular}

(version 2013.3520, denoted by V13 in Table 1) provided by the CDAAC (http://cdaac-www.cosmic.ucar. edu/cdaac/products.html), we also use the high-resolution COSMIC RO atmospheric profiles (denoted by V16 in Table 1) retrieved by modifying several parameters in the inversion algorithm. For the V16 profiles, we change the transition height between GO and WO from 20 to $30 \mathrm{~km}$ and fix the vertical resolution of PM method to $0.1 \mathrm{~km}$. The ionospheric correction is still based on extrapolation of GO-processed L1 and L2 bending angles. Consequently, the V16 profiles have vertical resolution of $0.1 \mathrm{~km}$ from the bottom to $30 \mathrm{~km}$. These profiles are retrieved for COSMIC occultations collocated with high-resolution radiosondes (see section 3) in the period from June 2006 to April 2014 used in this study.

\section{b. High-resolution radiosonde observations}

Considering the high-resolution requirement, the amount of data available over the tropics, and the period overlapping with the COSMIC mission, we collect the high-resolution radiosonde data from the following databases:
1) U.S. Radiosonde Replacement System (RRS) dataset (Love and Geller 2012). Beginning in 2005, the National Weather Service (NWS) replaced its entire upper-air network from its Microcomputer Automatic Radio-Theodolite (MicroART) tracking system to RRS which utilizes GPS tracking. The full replacement was completed in late 2013. This dataset includes high-vertical-resolution (1-s resolution or about every $5 \mathrm{~m}$ through the atmosphere) upper-air soundings collected at 92 official NWS stations (69 sites in the contiguous United States, 13 in Alaska region, 1 in Caribbean, and 9 in Pacific region, identified with red dots in Fig. 1). Except one station located in the Southern Hemisphere $\left(-14.33^{\circ} \mathrm{N}\right)$, all others are in the Northern Hemisphere with the latitudinal coverage of $\left(6.97^{\circ}-71.30^{\circ} \mathrm{N}\right)$. The type of RRS radiosonde is the Lockheed Martin Sippican MarkIIA, using the chip thermistor to measure the temperature, having a solar radiation correction applied by the RRS software. The details of its measuring accuracy and resolution are listed in Table 2. The standard soundings are scheduled twice daily at 0000 and 1200 coordinated universal time (UTC), while

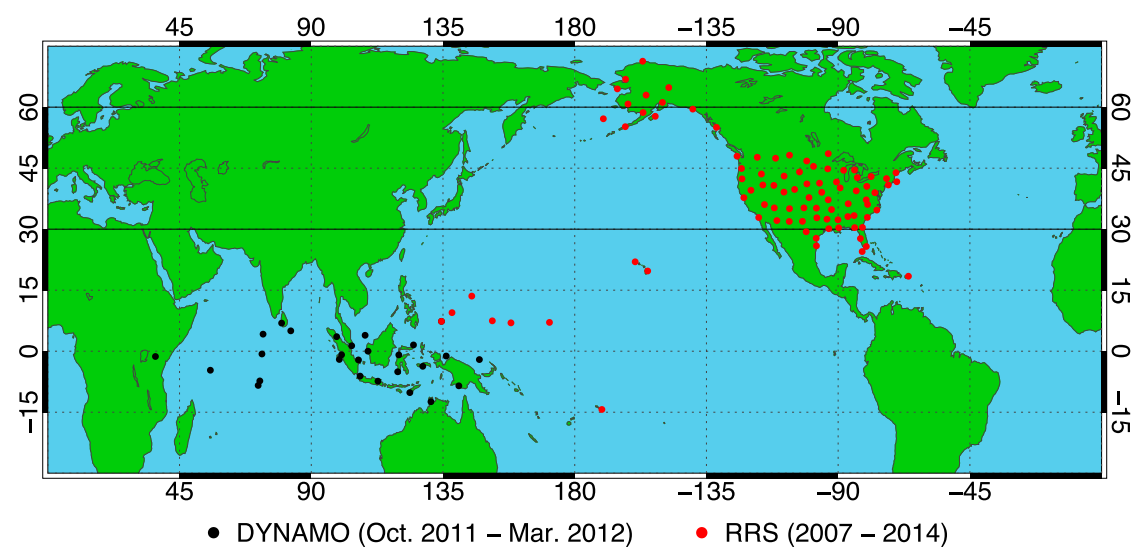

FIG. 1. High-resolution radiosondes located in the tropics collected from the RRS network (red) and DYNAMO campaign (black). More details of the DYNAMO radiosonde (including the sonde type, typical launch frequency, number of soundings, and so on) are available from Table 2 of Ciesielski et al. (2014). 
TABLE 2. Characteristics of radiosonde types used in this study.

\begin{tabular}{|c|c|c|c|c|c|c|}
\hline Type & Manufacturer & Temperature sensor & $\begin{array}{l}\text { Site radiation } \\
\text { correction }\end{array}$ & $\begin{array}{c}\text { Native } \\
\text { resolution (s) }\end{array}$ & $\begin{array}{l}\text { Temperature } \\
\text { resolution }\left({ }^{\circ} \mathrm{C}\right)\end{array}$ & $\begin{array}{l}\text { Temperature } \\
\text { accuracy }\left({ }^{\circ} \mathrm{C}\right)\end{array}$ \\
\hline LMS Mark IIA & Sippican & Chip thermistor & Solar & 1 & 0.1 & $\pm 0.5(2 \sigma)$ \\
\hline RS06G & Meisei & Rod thermistor & Solar & 1 & 0.1 & $\pm 0.5(2 \sigma)$ \\
\hline RS92 & Vaisala & Thin-wire F-Thermocap & Solar and IR & $1-2$ & 0.1 & $\pm 0.5(2 \sigma)$ \\
\hline M2K2-DC & Modem & Bead thermistor & Solar and IR & 1 & 0.1 & $\pm 0.5(2 \sigma)$ \\
\hline
\end{tabular}

the actual release times may be up to 60 min earlier. The RRS data are archived in BUFR format and available from NOAA's National Centers for Environmental Information (ftp://ftp.ncdc.noaa.gov/pub/ data/ua/rrs-data/bufr).

2) High-vertical-resolution upper-air sounding dataset for Dynamics of the Madden-Julian Oscillation (DYNAMO) field campaign during October 2011March 2012 (Ciesielski et al. 2014). During this period, high-resolution data ( 1 or $2 \mathrm{~s}$ ) were collected at 11 enhanced sites (by increasing the sounding frequency above normal operational frequency or performing operations at the sites where they were not previously performed) over the Indian Ocean region and 21 priority sounding sites (PSS) operated by many different countries (identified with black dots in Fig. 1). Four different radiosonde types are included in this dataset (see Table 2), and corrections for radiation error were applied at the sites before the data were transmitted. Some are corrected only for solar radiation, while others are corrected for both solar and infrared (IR) radiation.

\section{Comparison of high-resolution temperature profiles between $\mathrm{RO}$ and radiosonde}

A radiosonde can reach over $30-\mathrm{km}$ height and drift more than $100 \mathrm{~km}$ from the release point before the balloon bursts (Laroche and Sarrazin 2013). A representative ascent time is about $2 \mathrm{~h}$. For RO observations, the horizontal drift of the ray tangent point depends on the ray bending and occultation geometry. This results in the average horizontal tangent point drift of about $50 \mathrm{~km}$ (less than $100 \mathrm{~km}$ for most ROs) between 10 and $30 \mathrm{~km}$. To partially account for this drift in the collocation search, instead of using the release location of the radiosonde and the standard $\mathrm{RO}$ location parameters given in atmPrf files, we use the observed location and time at $20 \mathrm{~km}$. We also test the standard deviations of RO minus radiosonde observations temperature under different collocation criteria (100-300-km spatial and 1-3-h temporal difference) to understand the effect of spatial and temporal mismatch between RO and radiosonde profiles. Collocations within $200 \mathrm{~km}$ and $3 \mathrm{~h}$ result in a rather stable standard deviation that does not change significantly with the decrease of the spatial and temporal differences (not shown). With this criterion, we can find RO observations collocated with 241 radiosonde soundings from the DYNAMO experiment and 2997 soundings from the RRS dataset over the tropical region. Figure 2 gives an example of a temperature profile from a high-resolution radiosonde in black, along with three nearby $\mathrm{RO}$ profiles retrieved by the standard V13 (dashed) and high-resolution V16 schemes (solid) in colors. Each RO profile is shifted by $5 \mathrm{~K}$ for better visualization. It is seen that all profiles agree well in large-scale structures, including the tropopause and the inversion layer at $12-13 \mathrm{~km}$. As expected, the standard RO profiles show less small-scale structures. Correlation between small-scale structures from highresolution $\mathrm{RO}$ and radiosonde tends to decrease with height. This is related to the effect of observational noise which increases with height (discussed in section 1). Since in this study we are more interested in the small-scale atmospheric structures, we apply a stricter collocation criterion, $100 \mathrm{~km}$ and $1 \mathrm{~h}$, and find a total of $25+$ 268 COSMIC RO and radiosonde (DYNAMO + RRS) pairs at low latitudes $\left(15^{\circ} \mathrm{S}-30^{\circ} \mathrm{N}\right), 2223$ pairs at midlatitudes $\left(30^{\circ}-60^{\circ} \mathrm{N}\right)$, and 128 pairs at high latitudes $\left(60^{\circ}-75^{\circ} \mathrm{N}\right)$.

As outlined in the introduction, the main goal of this study is to answer a general question: Down to what scale does GPS RO realistically represent the vertical structure of the atmosphere in the upper troposphere and lower stratosphere? This minimal scale depends on the maximal physical resolution of GPS RO, but also is affected by the representativeness errors related to horizontal inhomogeneity of the atmosphere and by the measurement noise. In this study, we estimate this minimal "representative" scale by high-pass filtering the temperature profiles for closely collocated (in space and time) high-resolution GPS RO and radiosonde and calculating the cross-correlation coefficients for different filtering windows.

Figure 3 a gives an example of collocated temperature profiles from a radiosonde (in blue) and a GPS RO V16 (in red) with spatial and temporal differences of $87.7 \mathrm{~km}$ and $0.63 \mathrm{~h}$. Similar to Fig. 2, the two profiles, generally, agree well with the differences of about $1-2 \mathrm{~K}$ increasing 


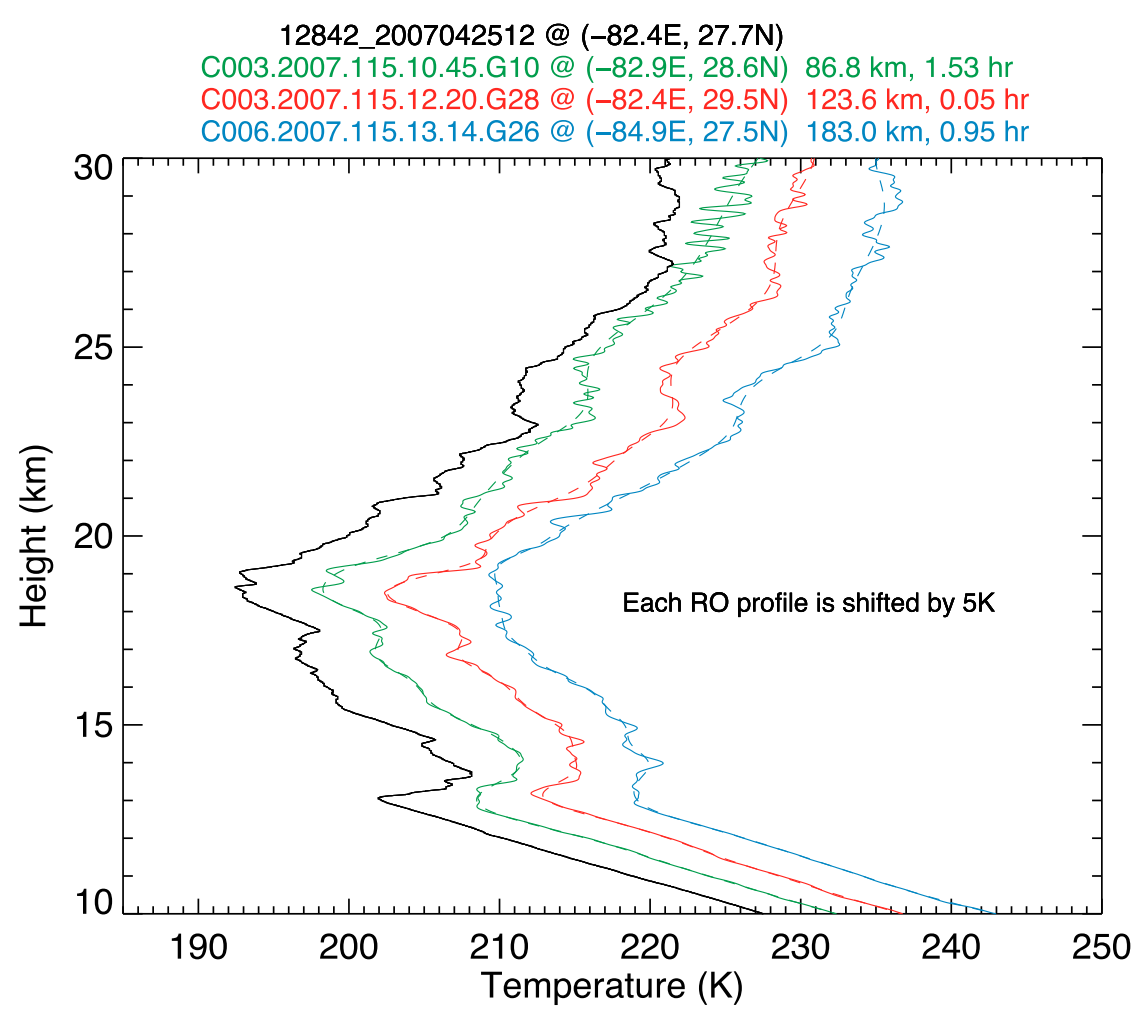

FIG. 2. Temperature profiles from the high-resolution radiosonde (black) along with three nearby ROs (in colors) obtained from the standard CDAAC output (V13) and highresolution retrievals in this study (V16). The IDs of radiosonde and ROs (along with the spatial and temporal distances from the radiosonde) are listed on top of the plot.

to $2-3 \mathrm{~K}$ above $\sim 23 \mathrm{~km}$. Tsuda et al. (2011) concluded that the maximal height of GPS RO for resolving vertically small-scale structures with scales $<0.5 \mathrm{~km}$ is about $27 \mathrm{~km}$ due to ionospheric residual effects. Therefore, we use the height interval $20-27 \mathrm{~km}$ for the cross-correlation analysis and apply a series of high-pass filterings with the filter window changing from 0.2 to $2.0 \mathrm{~km}$. As an example, Fig. $3 \mathrm{~b}$ shows the high-pass filtered temperature anomalies from the GPS RO (red) and radiosonde (blue) with filter windows of 200, 300, 500, and $800 \mathrm{~m}$. As expected, the amplitudes of temperature anomalies decrease with the decrease of the filter window. Figure $3 \mathrm{c}$ shows the cross-correlation coefficient between the GPS $\mathrm{RO}$ and radiosonde temperature anomalies (calculated in height interval $20-27 \mathrm{~km}$ ) as a function of the filter window. The cross-correlation coefficient reduces from 0.7 to 0.3 when the filter window reduces from 800 to $300 \mathrm{~m}$ and has an "elbow" at the filter window of about $500 \mathrm{~m}$.

\section{a. Effective vertical resolution of $R O$ based on cross-correlation analysis}

To account for the difference of the observation geometries between RO (limb) and radiosonde (local) and the spatial and temporal differences between them, hereafter we calculate the cross-correlation coefficients for not only different filter windows (ranging from 0.1 to $1.5 \mathrm{~km}$ ), but also for different vertical shifts (ranging from -0.5 to $+0.5 \mathrm{~km}$ ) between the GPS RO and radiosonde temperature profiles. Figures $4 a-d$ show four examples of high-resolution temperature profiles from radiosonde (black), standard RO V13 (red), and highresolution RO V16 (blue) in tropics. All three profiles generally agree well in large scales, though RO V13 clearly shows less small-scale structures compared with the other two. Figures $4 \mathrm{e}-\mathrm{h}$ show the cross-correlation coefficients between radiosonde and RO V16 in the interval $14-19 \mathrm{~km}$, considered as the tropical tropopause layer (Fueglistaler et al. 2009), as two-dimensional functions of the filtering window and the vertical shift. Figures $4 \mathrm{i}-1$ show results of the same cross-correlation analysis, but applied in the interval above the tropopause, $22-27 \mathrm{~km}$, where the low-intrinsic-frequency inertial GWs, mainly caused by convection, are dominant structures. The maximum of the cross-correlation coefficient for a given filtering window (denoted as COEF), generally increases with the increase of the filtering window, which is expected. The vertical lags of the COEF are close to zero in most cases, but can be as 

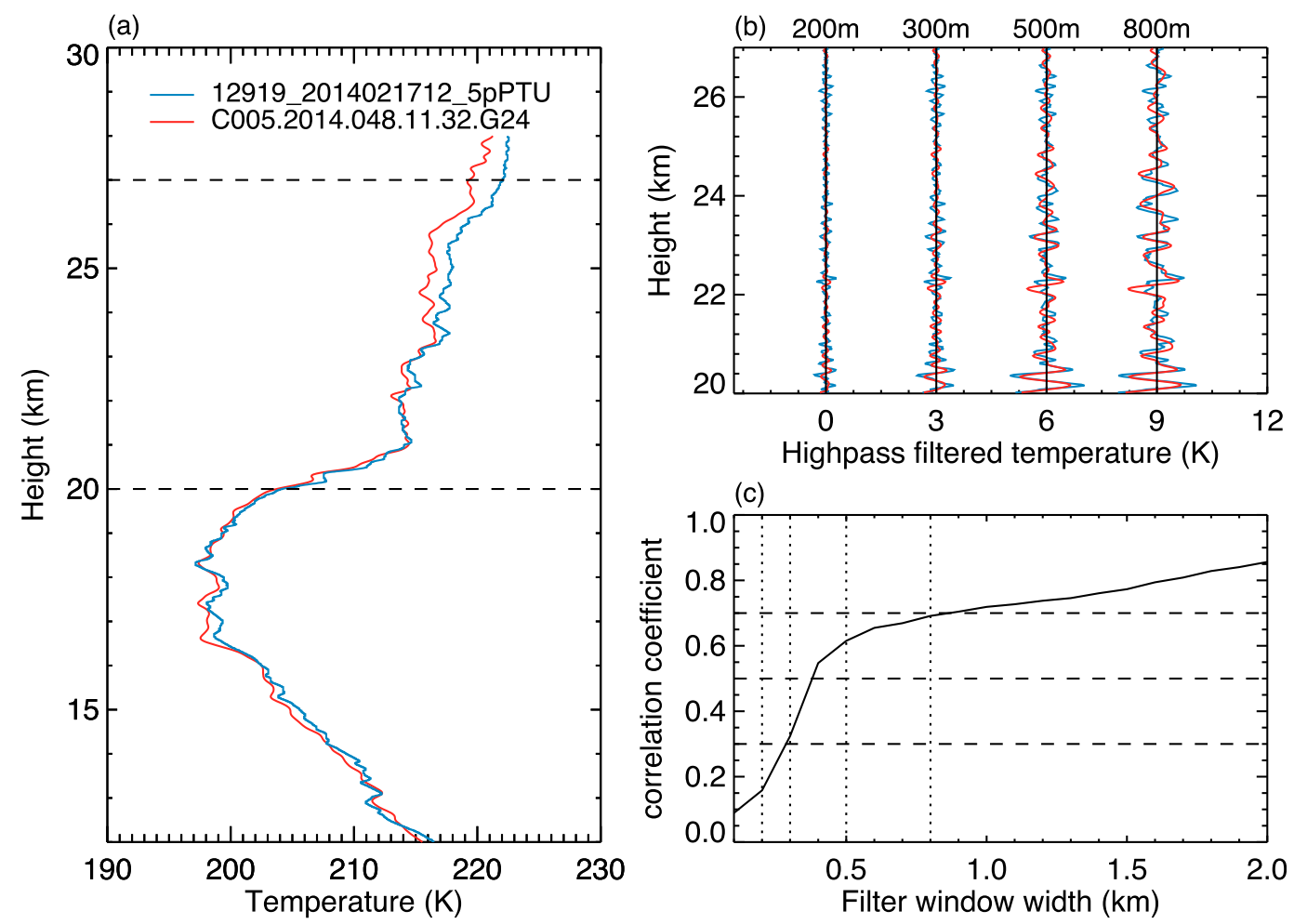

(c)

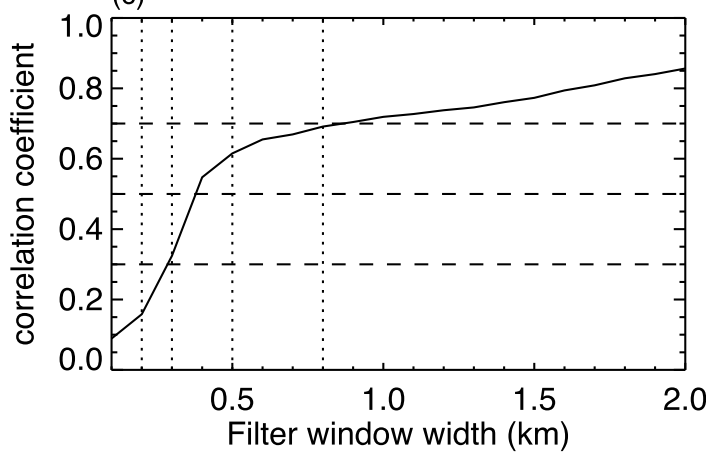

FIG. 3. (a) An example of collocated temperature profiles from the high-resolution radiosonde (blue) and RO V16 (red); (b) high-pass filtered temperature anomalies of radiosonde and RO V16 with the filter windows of $200,300,500$, and $800 \mathrm{~m}$; (c) cross-correlation coefficient of the high-pass filtered temperature anomalies from the radiosonde and RO V16 as a function of the filter windows changing from 0.2 to $2.0 \mathrm{~km}$.

large as $0.2 \mathrm{~km}$ (such as in Fig. 4j). The quasi periodicity of the cross-correlation coefficient in lag (which can be seen in some cases, at certain filtering window widths) can be related to quasi-periodic temperature variations, pronounced for certain vertical scales. Overall, COEFs are somewhat higher for 14-19-km interval than for 22-27-km interval.

Figures $5 \mathrm{a}$ and $5 \mathrm{~b}$ show the COEFs in the intervals 14-19 and $22-27 \mathrm{~km}$ as functions of the filtering window (ranging from 0.1 to $1.5 \mathrm{~km}$ ) for all 292 collocated RO and radiosonde pairs at the low latitudes. The COEFs are spread quite widely. For temperature fluctuations with vertical scales of about $1 \mathrm{~km}$, the maximum COEFs between $\mathrm{RO}$ and radiosonde can be as large as $\sim 1$ for 14 19 -km interval and $\sim 0.8$ (close to $\sim 1$ for two collocations) for $22-27-\mathrm{km}$ interval. If we use 0.7 as the threshold for statistically significant correlation (which accounts for $49 \%$ of the variability between RO and radiosonde; Cameron and Windmeijer 1997), the corresponding filtering window widths would be $\sim 0.2 \mathrm{~km}$ for $14-19-\mathrm{km}$ interval and $\sim 0.5 \mathrm{~km}$ for $22-27-\mathrm{km}$ interval. Atmospheric structures with smaller vertical scales would be mainly related to local processes; that is, they have insufficient anisotropy to comply with the assumption of locally spherical symmetry; thus, such structures cannot be well retrieved by RO. In addition, the effect of measurement noise also decreases $\mathrm{COEF}$ for small filtering windows. Figures $5 \mathrm{a}$ and $5 \mathrm{~b}$ suggest that $\sim 0.2$ - and $\sim 0.5-\mathrm{km}$ filtering windows may be considered optimal for WO inversions in the tropical tropopause layer and in the lower stratosphere respectively in the sense that these windows would not underresolve the atmospheric structures for all ROs (though they may be too small for some ROs). Larger windows would underresolve the atmospheric structures for some ROs while smaller windows would not result in realistic retrievals of the small-scale atmospheric structures for all ROs.

Next, we estimate the variation of the effective resolution of the GPS RO with height from the upper troposphere to lower stratosphere, in the interval $10-27 \mathrm{~km}$. For this purpose, we estimate the effective resolution in 5-km moving interval using 2-km step. In each $5-\mathrm{km}$ interval, we perform the cross-correlation analysis as discussed above and estimate the maximum COEF for all collocated GPS RO-radiosonde pairs, for each filtering window. This corresponds to the upper envelopes of the scatterplots such as those shown in Figs. 5a and 5b. Figure 5c shows such envelopes for all $5-\mathrm{km}$ intervals (indicated in the figure). According to 
(a) 12919_2014021712_5pPTU

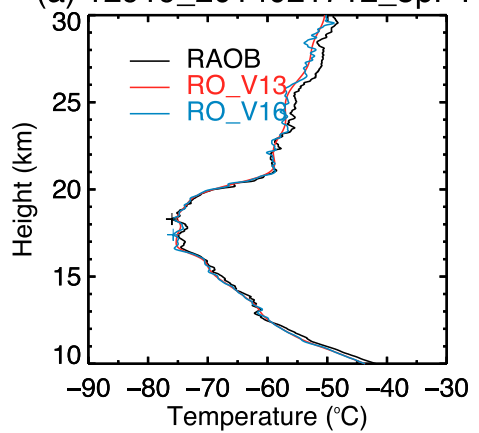

(b) 22010_2009122600_5pPTU

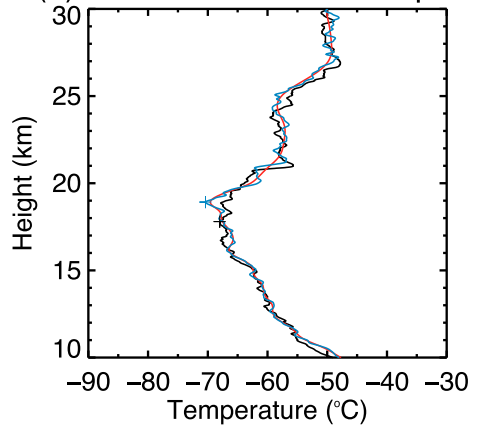

(c) Gan_ARM_20111011

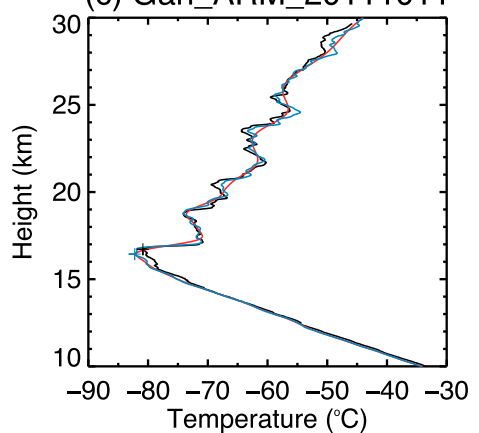

(d) Indonesia_Ambon_20111209

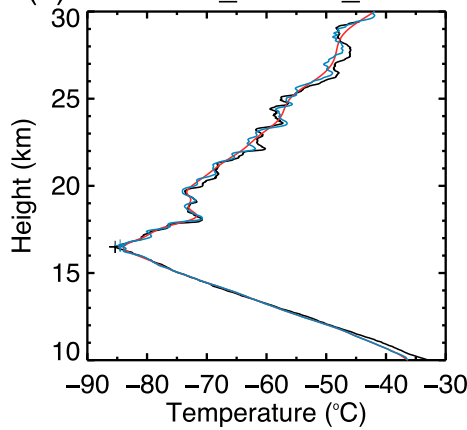

(e) C005.2014.048.11.32.G24

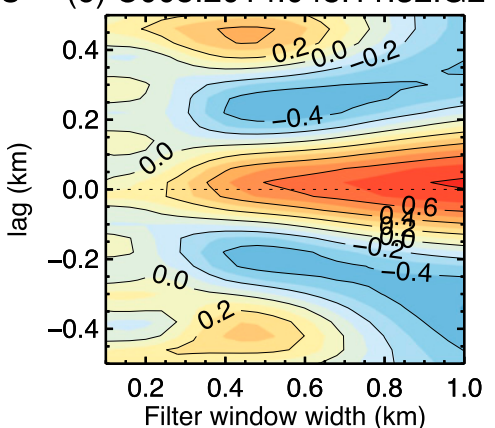

(f) C004.2009.360.00.26.G29

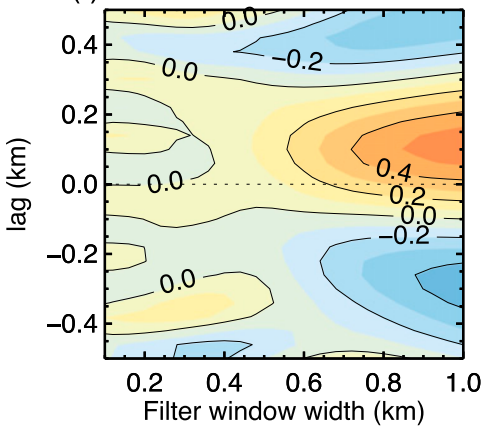

(g) C004.2011.284.09.54.G29

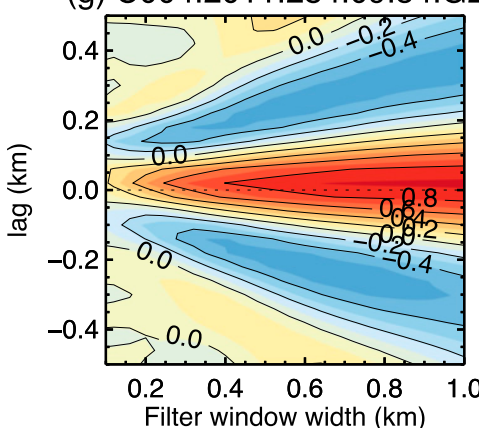

09 (h) C002.2011.344.00.21.G30

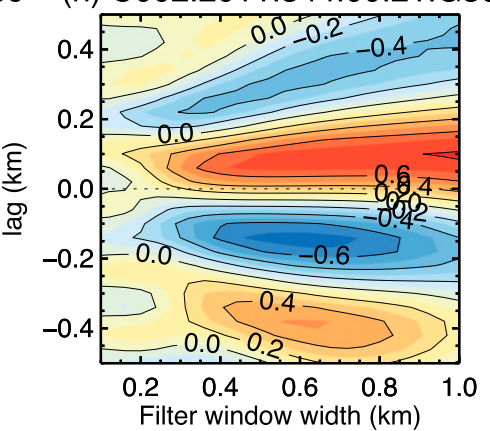

(i) C005.2014.048.11.32.G24

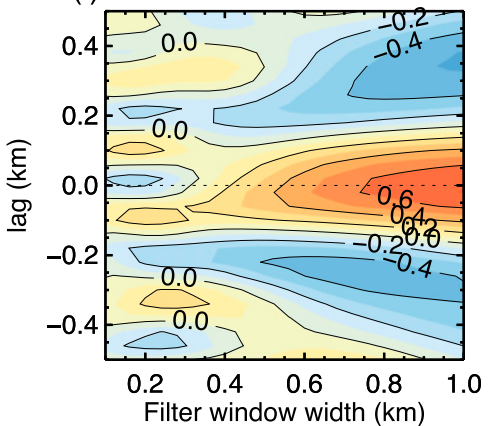

(j) C004.2009.360.00.26.G29

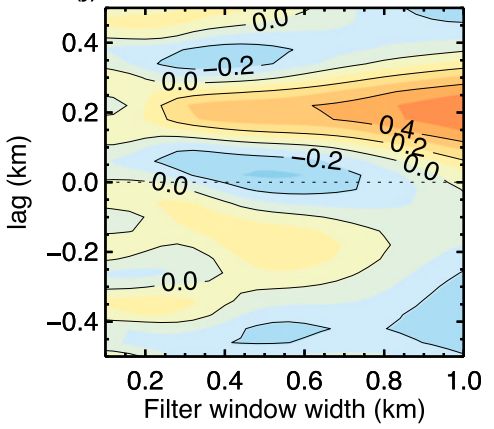

(k) C004.2011.284.09.54.G29

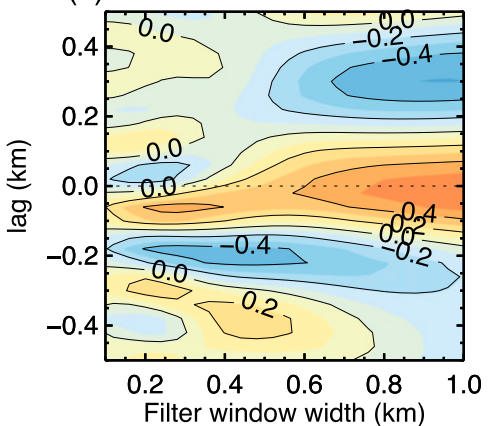

(I) C002.2011.344.00.21.G30

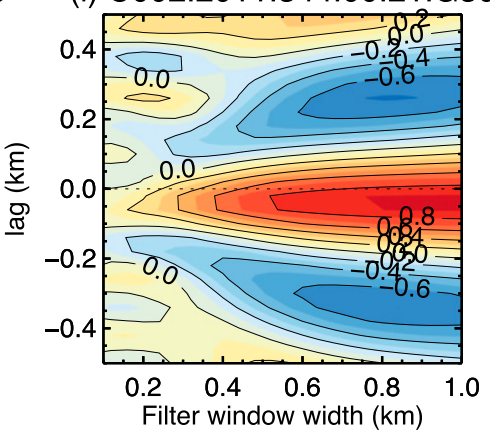

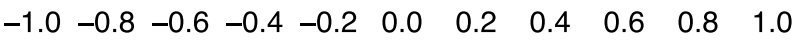

FIG. 4. (a)-(d) Temperature profiles from GPS RO V13 (red), V16 (blue), and from the RSS and DYNAMO campaign. (e)-(h) Crosscorrelation coefficients of the high-pass filtered temperature profiles in 14-19-km-height interval as functions of the filter window and lag. (i)-(l) As in (e)-(h), but in 22-27-km-height intervals. 
$14-19 \mathrm{~km}$

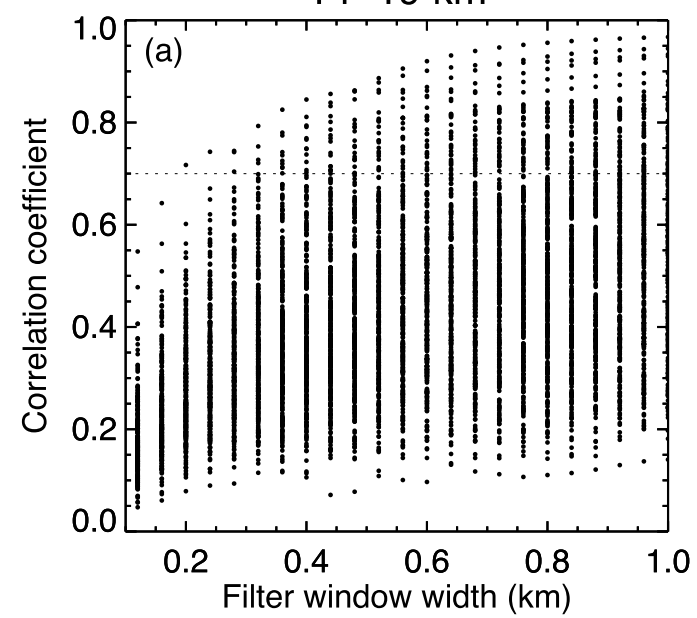

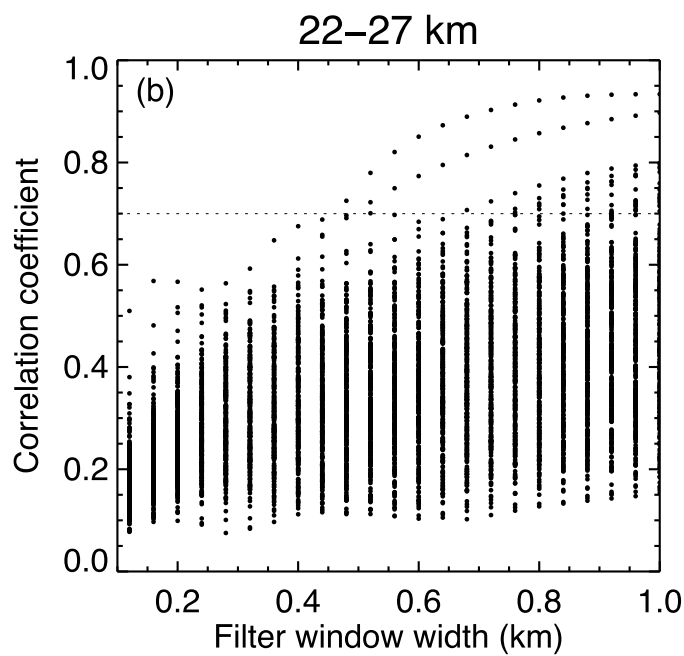

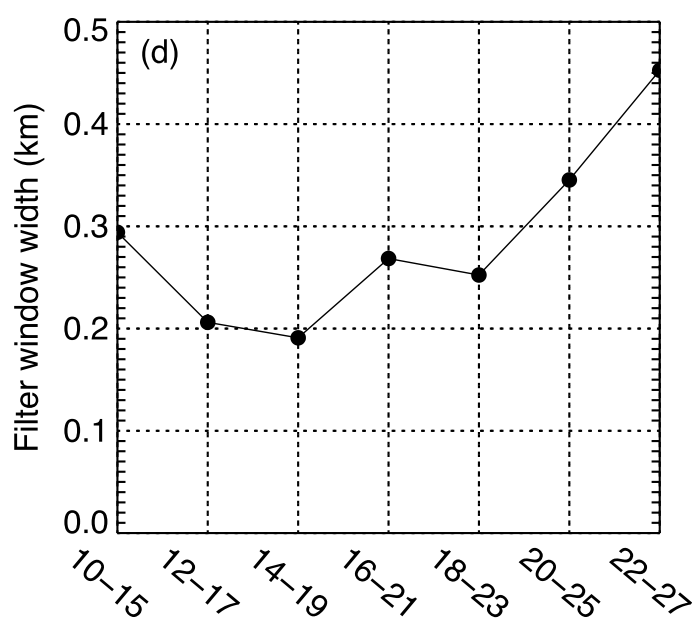

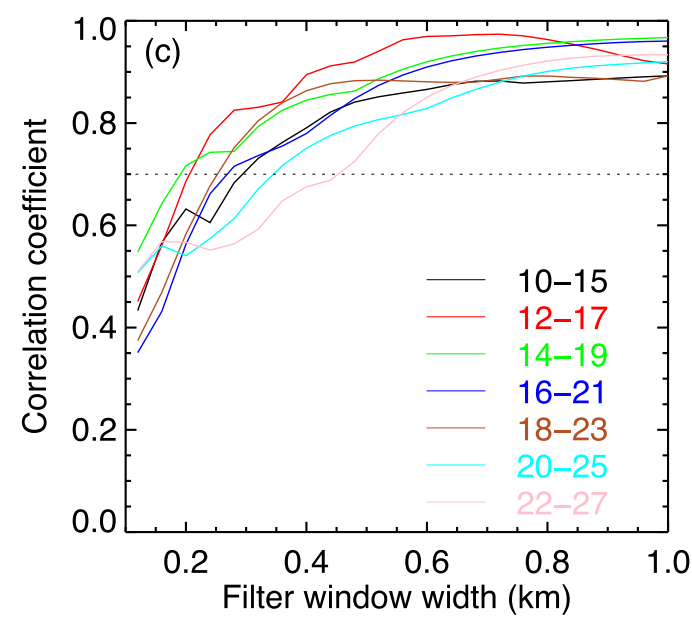

Height range $(\mathrm{km})$

FIG. 5. (a),(b) Maximum cross-correlation coefficients (COEF) for all collocated radiosonde and RO V16 pairs at low latitudes $\left(15^{\circ} \mathrm{S}-30^{\circ} \mathrm{N}\right)$ for different high-pass filter window widths in height intervals (a) 14-19 and (b) $22-27 \mathrm{~km}$. (c) Upper envelopes of the COEFs as functions of the filter window width for different height intervals (denoted by colors as indicated in the panel). (d) Filter window widths for which COEF equals 0.7 (effective resolution) for all height intervals from (c).

our definition, the filter window at which an envelope equals 0.7 is considered to be the effective resolution for the corresponding height interval. Figure $5 \mathrm{~d}$ summarizes the effective resolutions for different height intervals. It is seen, that the best resolution, $\sim 0.2 \mathrm{~km}$ is achieved around the tropical tropopause layer $(14-19 \mathrm{~km})$. The resolution degrades upward to about $0.5 \mathrm{~km}$ at 22 $27 \mathrm{~km}$, but also degrades downward to about $0.3 \mathrm{~km}$ at $10-15 \mathrm{~km}$. As discussed earlier, the two contributors to the effective resolution are the atmospheric structures and the observational noises from RO. While fully separating them is difficult and outside the scope of this study, the degradation of the effective resolution upward is consistent with increasing effect of such RO observational noise as the ionospheric residuals (also the thermal and clock noises). Degradation of the effective resolution downward is consistent with the increasing effect of tropical convection which causes the fluctuation of RO signals and thus manifests itself as the observational noise.

We also apply the same cross-correlation analysis for the data at the mid- and high latitudes. However, we note that the radiosonde stations for mid- and high latitudes are all located over the continental United States (including mountain areas) and thus have limited longitudinal coverage. This could affect our results due to the horizontal inhomogeneity of the topographic internal GWs. Figure 6 presents the maximum COEFs 

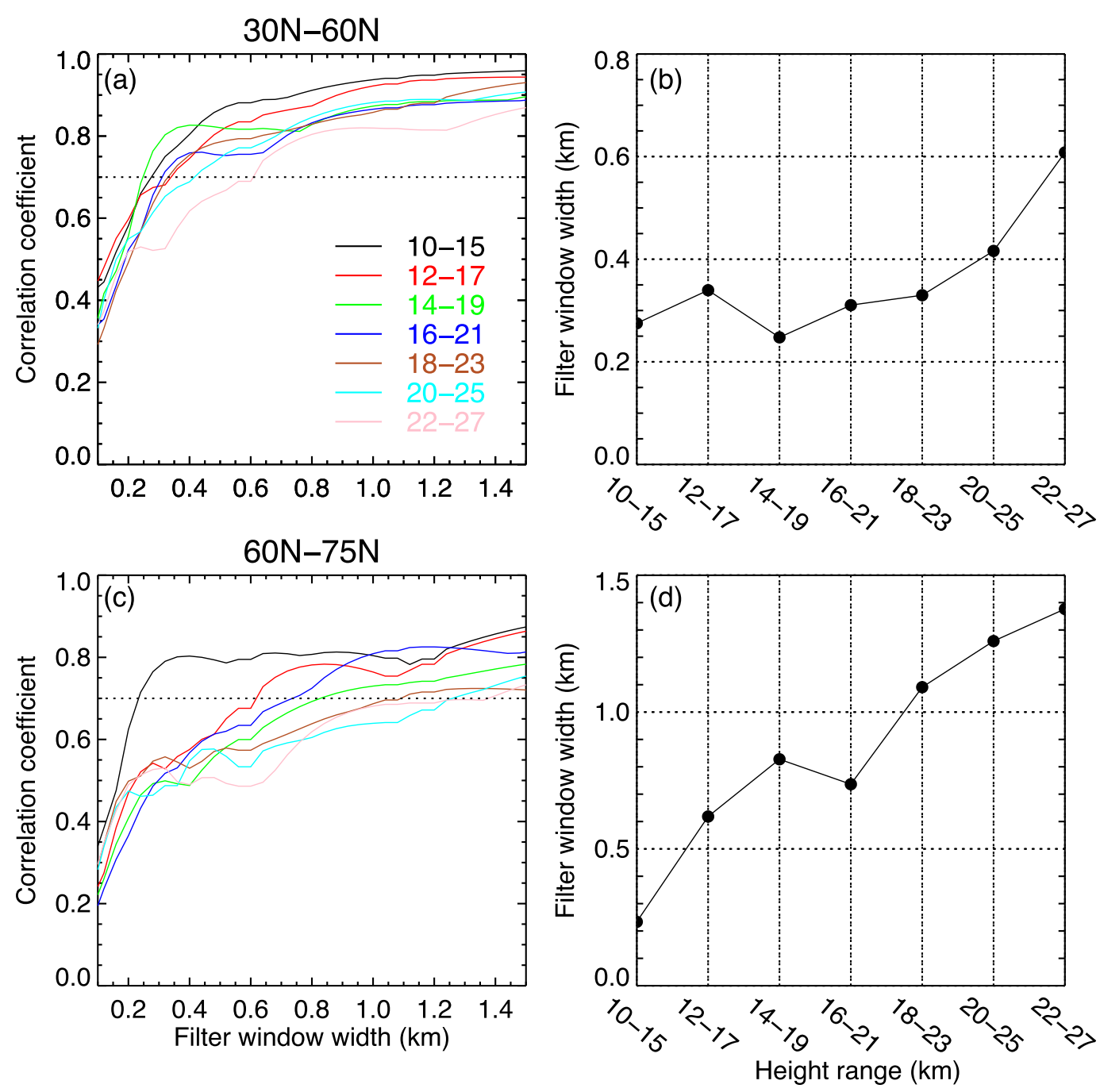

FIG. 6. (a),(b) As in Figs. 5c,d, but for midlatitudes $\left(30^{\circ}-60^{\circ} \mathrm{N}\right)$. (c),(d) As in (a),(b), but for high latitudes $\left(60^{\circ}-75^{\circ} \mathrm{N}\right)$.

among all collocated GPS RO and radiosonde pairs for each 5-km interval from 10 to $27 \mathrm{~km}$ (Figs. 6a,c) and the estimated effective resolutions for the corresponding different altitude intervals (Figs. 6b,d) for the mid(Figs. 6a,b) and high (Figs. 6c,d) latitudes, similar to Figs. $5 \mathrm{c}$ and $5 \mathrm{~d}$. For the midlatitudes, the maximum COEFs (Fig. 6a) increase significantly from 0.3 to 0.8 when the filter window changes from 0.1 to $0.5 \mathrm{~km}$. The effective resolution (Fig. 6b) is varying between 0.2 and 0.4 at $\sim 10-23 \mathrm{~km}$, and degrades to $0.6 \mathrm{~km}$ at $22-27 \mathrm{~km}$. Degradation of the effective RO resolution in midlatitudes can be explained by distortion of atmospheric stratification related to the waves generated by topography or along the subtropical jet stream. The resolutions at midlatitudes can be worse than those at low latitudes because the wave structures at the low latitudes have longer horizontal wavelengths and shorter vertical wavelengths (Wang and Alexander 2010) and thus can be better resolved by RO. For the high latitudes, the maximum COEFs increase slowly with the filter window widths (Fig. 6c), except for the altitude interval 10-15 km. The effective resolutions at high latitudes (Fig. 6d) are the worst compared to other latitudes, and significantly increase from $\sim 0.2 \mathrm{~km}$ at $10-15-\mathrm{km}$ altitude to $\sim 1.4 \mathrm{~km}$ at $22-27-\mathrm{km}$ altitude. The deterioration of RO effective resolution with height can be explained by significantly enhanced effects of the polar vortex on the atmospheric horizontal inhomogeneity extending from the tropopause $(\sim 10 \mathrm{~km})$ to the stratopause $(\sim 50-55 \mathrm{~km})$ (Noersomadi and Tsuda 2017). We note that in high latitudes, though we use the data from all year-round, the maximum COEFs for all collocated GPS RO-radiosonde pairs are found mainly in summer season (April-September), which should be related to reduced planetary wave activity. 


\section{b. Impact of vertical resolution on cold-point tropical tropopause parameters}

For each occultation, in addition to retrieved vertical profiles (vectors), CDAAC also provides a set of scalar parameters. Among those parameters are tropopause temperature and height, which are both important for weather and climate applications. For instance, the tropopause temperature in the tropics controls the water vapor content that enters the stratosphere, and thus is fundamentally related to water vapor transport and cloud formation; while the height of the tropopause is considered a "fingerprint" for climate change in the upper troposphere and lower stratosphere (Santer et al. 2003). Investigation of the variations and trends of tropopause parameters requires the use of observations with sufficient vertical resolution, such as the highresolution radiosondes and RO. Below we use the temperature and height of the cold-point tropopause (defined as the local temperature minimum) derived from high-resolution radiosondes and from $\mathrm{RO}$, as an additional metric for investigation of the effective vertical resolution and optimal smoothing of RO.

At first, we use high-resolution (1 s) RRS radiosonde data only to quantify the impact of the vertical resolution on the cold-point tropopause parameters. We apply low-pass filtering with different windows for the highresolution radiosonde temperature profiles to simulate gradual degradation of the vertical resolution. Figures $7 \mathrm{a}$ and $7 \mathrm{~b}$ show the raw (unfiltered) high-resolution temperature profiles from two radiosonde soundings near the tropopause (plotted in black) along with 10 profiles, lowpass filtered with windows ranging from 25 to $925 \mathrm{~m}$ with a $100-\mathrm{m}$ step (plotted in colors). The cold-point tropopauses are identified by the corresponding color dots. Figure $7 \mathrm{a}$ shows the case with one significant minimum in the temperature profile. Degradation of the vertical resolution increases the tropopause temperature and reduces the tropopause height (the sign of the height change may be different depending on the shape of the temperature profile). In the case of several comparable local minima (such as in Fig. 7b), degradation of the vertical resolution increases temperatures of all local minima, but it also can result in random jumps of the absolute minimum between the local minima. Next, we apply low-pass filtering to all high-resolution radiosonde soundings collected at one station (WMO number: 40309) within a year. Figures 7c and $7 \mathrm{~d}$ show the differences of the tropopause temperature (Fig. 7c) and height (Fig. 7d) between filtered and original (unfiltered) temperature profiles for different filter window widths. Red thick and thin lines show mean and \pm standard deviation of the differences calculated for a given filter window width. It is seen that, on average, the tropopause temperatures increase about linearly with the increase of the filter window width, and this effect can reach $1.4 \mathrm{~K}$ for a filter window width of $1 \mathrm{~km}$. The tropopause heights, on average, become slightly lower (by $0.1 \mathrm{~km}$ ) with the increase of the filter window up to $1 \mathrm{~km}$. As opposed to temperature differences, the distribution of height differences has outliers related to existence of two (or more) local temperature minima with small differences in temperatures, but large differences in height (as shown in Fig. 7b).

Next, we compare the cold-point tropopause parameters from RO and high-resolution radiosondes. Figures $8 \mathrm{a}$ and $8 \mathrm{~b}$ show the tropopause temperatures (Trtcp) and heights (Trhcp) retrieved by V13 (black) and V16 (red) RO processings and from collocated high-resolution radiosondes (292 pairs). The correlation coefficients of the tropopause temperatures between ROs and radiosondes are 0.97 for both RO V13 and V16 processings. The V13 processing shows a warm bias of $\sim 0.6 \mathrm{~K}$, which is significantly reduced in the V16 processing. For the tropopause heights, the results are qualitatively similar. Using the high-resolution radiosondes as the reference, the RO V16 shows similar correlation, smaller bias, and slightly larger standard deviation than those from V13. These results are consistent with Fig. 7, considering that V13 has vertical resolution of $1 \mathrm{~km}$ near the tropopause, while V16 has $100 \mathrm{~m}$. Figures $8 \mathrm{c}$ and $8 \mathrm{~d}$ show mean differences of the tropopause temperatures and heights between the radiosondes and the V16 processing after additional smoothing with filter windows of $0.1,0.15$, $0.2, \ldots, 0.5 \mathrm{~km}$. It is seen that the mean differences of the tropopause parameters increase with the increase of the filter window width. The correlation and standard deviation of the tropopause parameters between smoothed $\mathrm{RO}$ and radiosonde do not change significantly for filter windows between 0.1 and $0.5 \mathrm{~km}$ (not shown). In section $3 \mathrm{a}$, we arrived at a conclusion that the optimal RO resolution for the tropical tropopause layer is $\sim 0.2 \mathrm{~km}$. However, the resolution at the tropical cold-point tropopause is higher, about $100 \mathrm{~m}$, that is, close to physical resolution of the GPS RO due to significant vertical sharpness and horizontal homogeneity of this atmospheric structure. For specific applications that use the tropopause temperature and height, the highest resolution $(100 \mathrm{~m})$, even though it comes at the expense of increased noise, may be advantageous (this may need additional validation).

\section{Discussion and conclusions}

In this study, we investigated the effective vertical resolution of RO measurements in the upper troposphere and lower stratosphere $(10-27 \mathrm{~km})$. The effective 

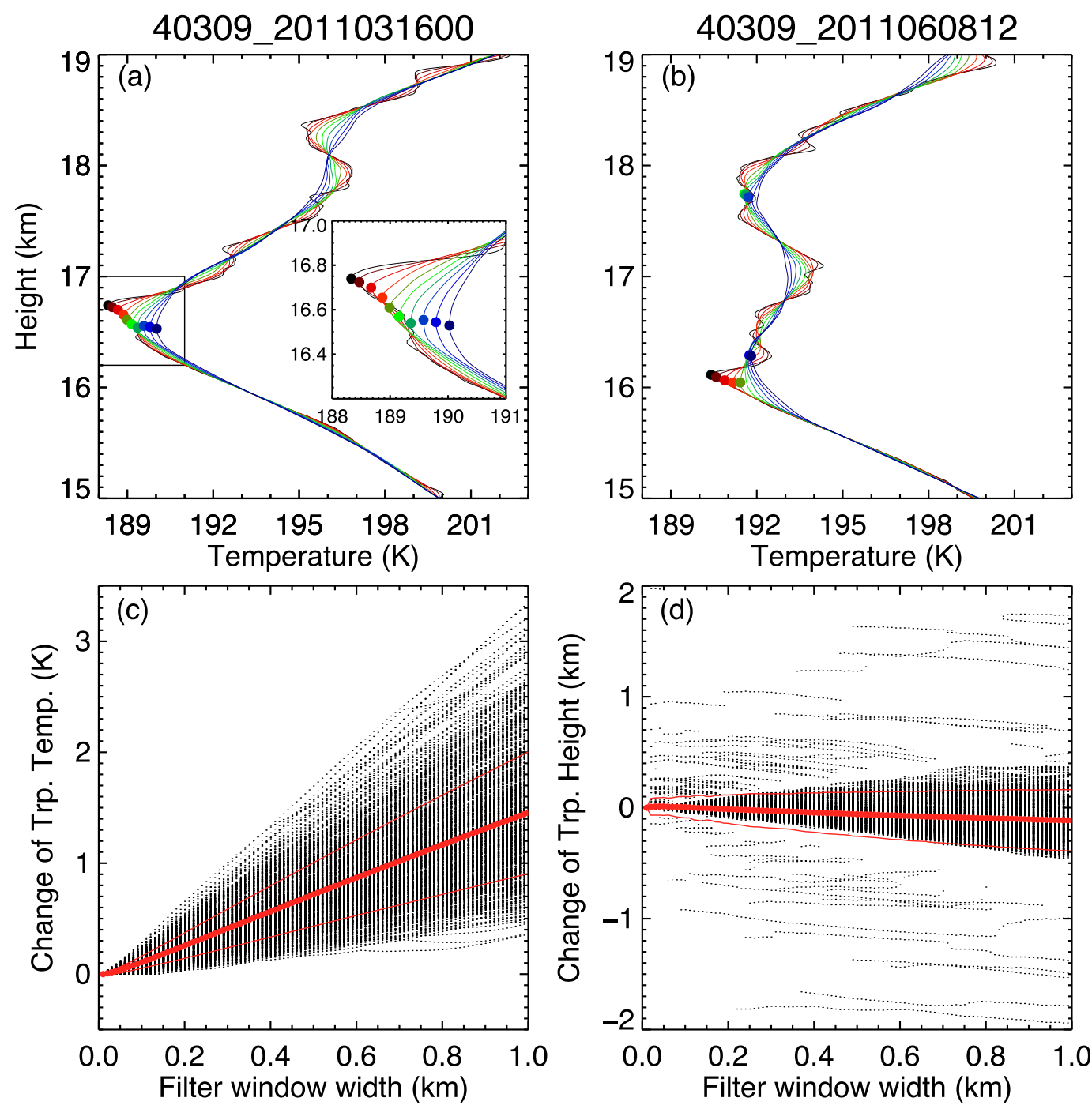

FIG. 7. (a),(b) Two examples of radiosonde temperature profiles smoothed with 10 different filter windows of 25, $125, \ldots, 925 \mathrm{~m}$. The positions of cold-point tropopause are identified by dots. (c),(d) Variations of the cold-point (left) tropopause temperature (right) and height as functions of smoothing window applied for high-resolution radiosonde temperature profiles collected during one year from one station (WMO number: 40309). Thick and thin red lines denote the mean and the standard deviation.

vertical resolution, in addition to previously studied physical vertical resolution (limited by diffraction effects in RO measurements), considers the effects of horizontal inhomogeneity of the real atmosphere and observational noise sources (ionospheric residuals, thermal noise, unmodeled clock effects) on the representativeness errors of retrieved profiles. The effective vertical resolution is directly related to the optimal smoothing of RO profiles in inversion algorithms. The smoothing scale should be a trade-off between representation of the vertical atmospheric structures at maximum possible resolution and suppression of the variations of retrieved profiles not correlated with those structures. The resulting smoothing is different from the physical resolution and is different in different height ranges and different latitudes.

Our study is based on comparison of collocated temperature profiles from GPS RO and high-resolution radiosondes. The GPS RO and radiosonde temperature profiles are subject to the same high-pass filtering with different cutoff wavenumbers. The cutoff wavenumber, at which the cross-correlation coefficient between the high-pass filtered profiles becomes statistically significant, is considered to be representative of the effective vertical resolution. The results indicate that for low latitudes $\left(15^{\circ} \mathrm{S}-30^{\circ} \mathrm{N}\right)$, the effective vertical resolution of $\mathrm{RO}$ above the tropopause $(22-27 \mathrm{~km})$ is $\sim 500 \mathrm{~m}$. In the 
(a)

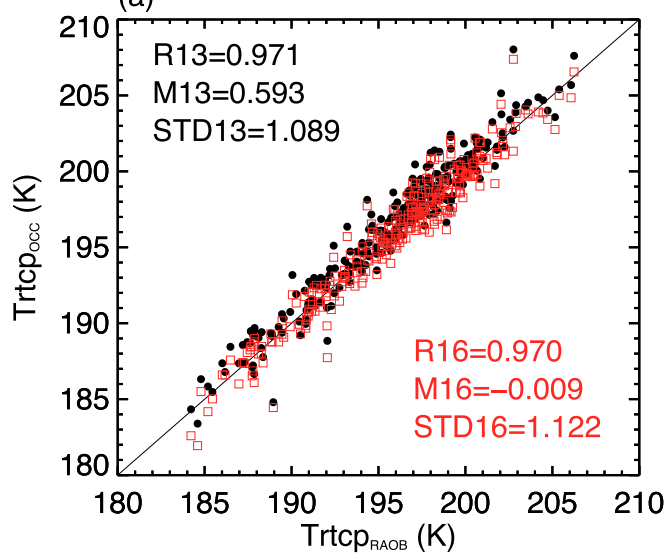

(c)

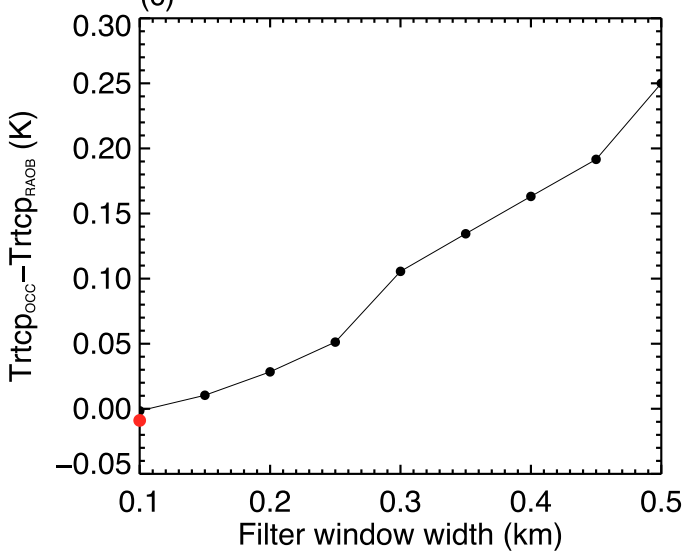

(b)

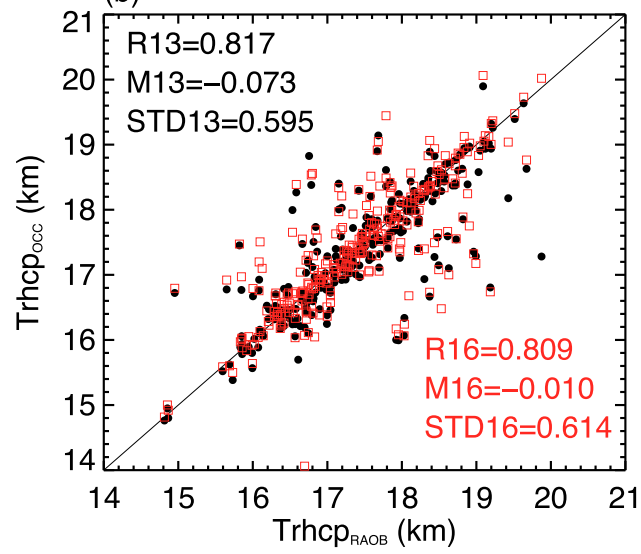

(d)

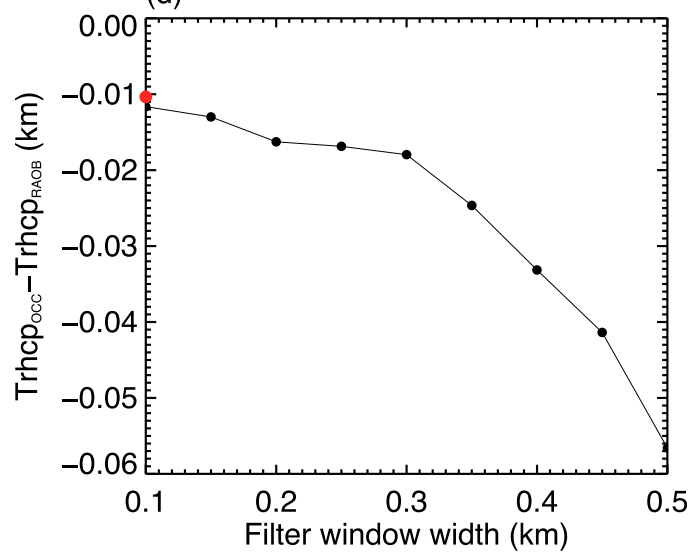

FIG. 8. Comparison of cold-point (a) tropopause temperature and (b) height between RO (V13 black dots, RO V16 red squares) and collocated high-resolution radiosondes (with vertical resolution of $20 \mathrm{~m}$ ); $R, M$, and STD denote the correlation coefficient, the mean, and standard deviations. Variations of the mean differences of the (c) tropopause temperature and (d) height between additionally filtered RO V16 and high-resolution radiosondes as functions of the filter window.

tropical tropopause layer $(14-19 \mathrm{~km})$, the effective vertical resolution of RO is $\sim 200 \mathrm{~m}$. For the midlatitudes $\left(30^{\circ}-60^{\circ} \mathrm{N}\right)$, the effective resolutions are slightly worse than those for low latitudes, varying from 0.2 to $0.6 \mathrm{~km}$ within $10-27 \mathrm{~km}$. For high latitudes $\left(60^{\circ}-75^{\circ} \mathrm{N}\right)$, the resolution is changing notably with height from $0.2 \mathrm{~km}$ at $10-15 \mathrm{~km}$ to a rather large number $\sim 1.4 \mathrm{~km}$ at $22-27 \mathrm{~km}$. The effective resolutions estimated at the low latitudes have better zonal representation since the radiosondes used in this study have better coverage along the longitudes from land to ocean areas. An additional metric is used to investigate the optimal resolution at the tropopause, based on direct comparison of cold-point tropopause (CPT) temperatures and heights calculated from GPS RO with different smoothing scales and from collocated high-resolution radiosondes without smoothing. It is found that the standard deviation of the CPT temperatures between GPS RO and radiosondes is about $1 \mathrm{~K}$ for both $100-$ and $500-\mathrm{m}$ smoothing scales, while the mean deviation reduces substantially from 0.25 to $-0.01 \mathrm{~K}$ when the smoothing scale reduces from 500 to $100 \mathrm{~m}$. Similarly, for the CPT height, the standard deviation is about $0.8 \mathrm{~km}$ for both smoothing scales, while the mean deviation reduces from -0.055 to $-0.01 \mathrm{~km}$ when the smoothing scale reduces from 500 to $100 \mathrm{~m}$. These results are important, especially for climate applications, as they suggest that for accurate monitoring of the tropical tropopause, an optimal smoothing scale around the tropopause should be close to physical resolution $(\sim 100 \mathrm{~m})$, that is, smaller than in the tropical tropopause layer $(200 \mathrm{~m})$ and substantially smaller than above the tropopause $(500 \mathrm{~m})$ where atmospheric variations are dominated by GWs. Similar results, but with smaller standard deviations and less pronounced reduction of the biases for high-resolution GPS RO processing, were obtained by Noersomadi and Tsuda (2017). The differences in the results may be related to different radiosondes, collocation criteria, and details of GPS RO 
processing. Based on our results, processing of $\mathrm{RO}$ data may be considered in different modes aimed at different applications.

Acknowledgments. We thank the UCAR CDAAC (http://cdaac-www.cosmic.ucar.edu/cdaac/) for the COSMIC atmospheric data, NOAA's National Centers for Environmental Information (ftp://ftp.ncdc.noaa.gov/pub/data/ ua/rrs-data/) for the RRS radiosonde data, and NCAR Earth Observing Laboratory (https://www.eol.ucar.edu/ field_projects/dynamo) for archiving the DYNAMO radiosonde data. This work is supported by the National Science Foundation under Cooperative Agreement AGS-1522830. The authors acknowledge the contributions to this work from members of the COSMIC team at UCAR.

\section{APPENDIX}

\section{Description of the Filtering}

Results of this study depend on the method of data smoothing (filtering). Therefore, it is important to characterize the filter in more detail. In this study we use a sliding polynomial regression, sometimes termed as the Savitzky-Golay filter (Press et al. 1992), as the low-pass filter (this filter currently is used for RO data processing at the CDAAC). The high-pass filtering consists of the calculation of residuals after the low-pass filtering. We apply a second-order polynomial (quadratic) fit in the sliding window of a fixed length for data sampled on a uniform grid. While it is common to use the length of the sliding window to approximately characterize the degree of smoothness (also used in this study), a more accurate characterization is provided by response functions. Below we first illustrate the effect of the filter by smoothing white Gaussian noise and then characterize this filter by impulse and period response functions.

Figure A1a shows white Gaussian noise with zero mean and unit variance before (black line) and after (red line) smoothing by sliding quadratic fit. The argument is normed by the length of the sliding window. In this example, the number of samples inside the window is 50. Figure A1b (red line) shows the impulse response function (normed by its value at maximum) of the same filter. Figure A1c (red line) shows the "period" response function (similar to the frequency response but plotted as the function of period instead of the frequency) of the same filter. Arguments in Figs. A1b and A1c are normed by the length of sliding window. It is seen from Fig. A1a that the sliding quadratic fit passes structures with scales much smaller than the sliding window. This effect
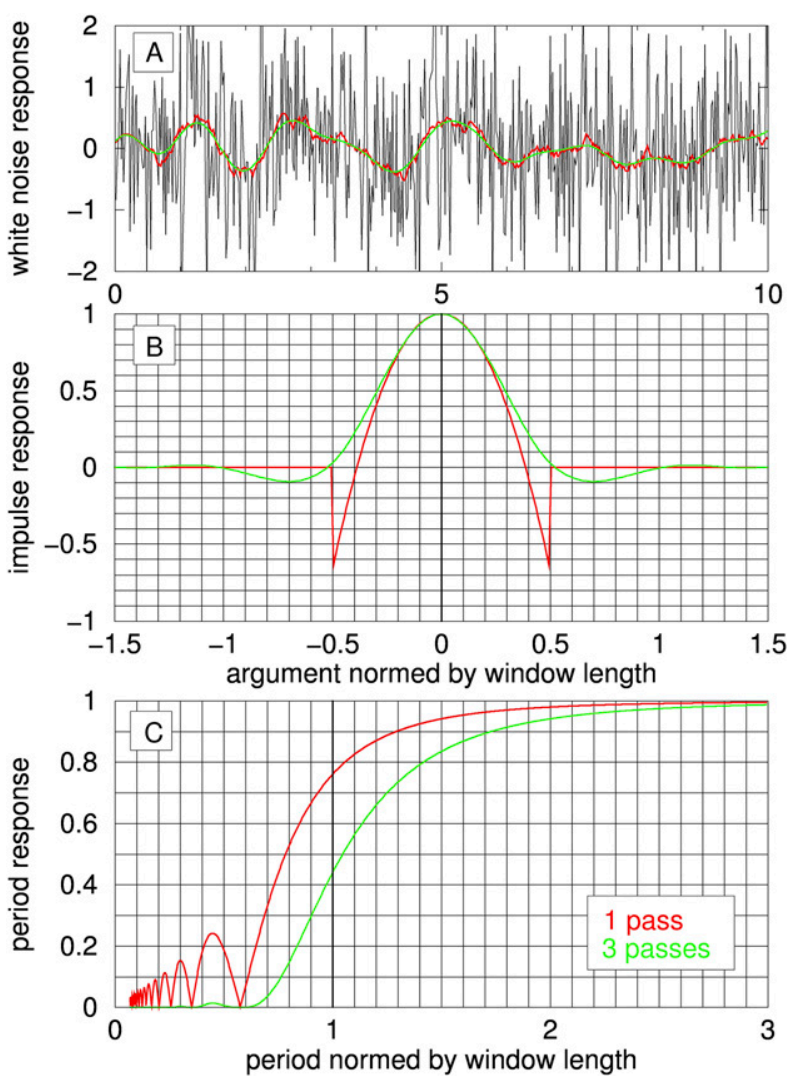

FIG. A1. (a) An example of white Gaussian noise (black) and the results of filtering. (b),(c) Impulse and period response functions. Filter: sliding quadratic fit; 1 application (red), 3 applications (green). Arguments on all panels are normed by the length of sliding window.

corresponds to the discontinuities of the impulse response function at \pm 0.5 (Fig. A $1 b$ ) and to the side lobes of the period response function at $0.45,0.3, \ldots$ (Fig. A1c). One way to better suppress these small-scale structures is to apply the same filter several times. The results of applying the filter three times (called 3-times), are shown by green lines in Figs. A1a-c. It is seen that the small-scale residuals of white noise are significantly suppressed (Fig. A1a), which corresponds to suppression of discontinuities in the impulse response function (Fig. A1b) and side lobes in the period response function (Fig. A1c). This also results in reduction of the amplitude response to a harmonic with a period equal window length $(=1)$ from $\sim 0.76$ to $\sim 0.44$ (Fig. A1c). Cutoff periods, using $-3 \mathrm{~dB}(-6 \mathrm{~dB})$ conventions, are $\sim 0.8$ $(\sim 0.92)$ and $\sim 1.05(\sim 1.25)$ for 1-time and 3-times sliding quadratic fit filters. The 3 -times sliding quadratic fit is the filter of choice in this study (and currently, of the CDAAC processing).

In RO data processing, filtering is applied at different steps, for different functions defined in different domains. In GO processing, filtering is applied for the 


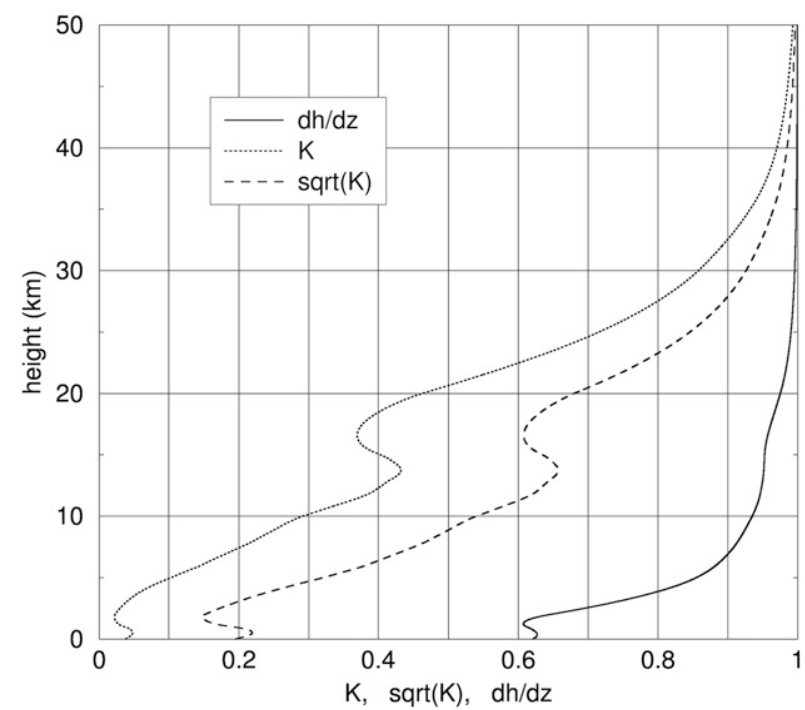

FIG. A2. Vertical profiles of $d h / d z$ (for conversion of the filtering windows in $h$ and $z$ ), defocusing factor $K$ (for conversion of the filtering windows in $h$ and $t$ ), and $\sqrt{K}$ (for conversion of the Fresnel zone).

Doppler defined as a function of time, while in WO processing for bending angle as a function of impact height. In this study, additionally, filtering is applied for the temperature as a function of height. Below we outline relations between the filtering windows $w_{t}, w_{h}, w_{z}$ in time $t$, impact height $h$, and height $z$ domains. In linear approximation, these relations are given by the derivatives $w_{h} / w_{z} \approx d h / d z$ and $w_{h} / w_{t} \approx d h / d t$.

As it follows from the definition of impact parameter (height) (Kursinski et al. 1997): $d h / d z=1+r d n / d z$, where $n$ is refractive index and $r$ is radius. An example of $d h / d z$, calculated for the tropical moist climatology model (Kirchengast et al. 1999), is shown in Fig. A2. It is seen that above the troposphere, $d h / d z \approx 1$ and thus $w_{h} \approx w_{z}$ at heights considered in this study.

The relation between $w_{h}$ and $w_{t}$ depends on differential bending (defocusing), which reduces the ratio of vertical velocity of ray tangent point to velocity of straightline GPS-LEO $v_{\perp}$. Taking into account the differential bending, $d h / d t=K v_{\perp}$ where $K \approx 1 /(1-L d \alpha / d h)$ is the defocusing factor ( $L$ is the distance from ray tangent point to LEO) (Kursinski et al. 1997). An example of $K(z)$, calculated for the tropical moist climatology model (Kirchengast et al. 1999) and LEO in 750-km orbit, is shown in Fig. A2. Thus, smoothing with a constant window in time $w_{t}$ (for GO processing) is equivalent to smoothing with the impact height window $w_{h}=K w_{t} v_{\perp}$ which reduces with decreasing height. We note that the vertical size of the first Fresnel zone, which is related to the physical resolution of the GO inversion, also reduces due to differential bending, but more slowly, proportionally to $\sqrt{K}$ (Kursinski et al. 1997), also shown in Fig. A2.

For L1 GPS frequency, the wavelength $\lambda \approx 19 \mathrm{~cm}$, the Fresnel zone above the atmosphere $F_{0} \approx 2 \sqrt{\lambda L} \approx 1.5 \mathrm{~km}$. In V13, for GO processing, $w_{t}$ is set to $2 F_{0} / v_{\perp}\left(v_{\perp}\right.$ is determined individually for each occultation). This corresponds to $w_{h}=K w_{t} v_{\perp}$ changing from $\sim 3 \mathrm{~km}$ above the atmosphere to $\sim 1.4 \mathrm{~km}$ at 20 -km height (shown in Table 1) where the Fresnel zone $\sqrt{K} F_{0}$ is about $\sim 1 \mathrm{~km}$. For WO processing in V13, $w_{h}$ changes stepwise from $0.2 \mathrm{~km}$ at surface to $1 \mathrm{~km}$ at $20-\mathrm{km}$ height (also shown in Table 1).

\section{REFERENCES}

Ahmad, B., and G. L. Tyler, 1998: The two-dimensional resolution kernel associated with retrieval of ionospheric and atmospheric refractivity profiles by Abelian inversion of radio occultation phase data. Radio Sci., 33, 129-142, https://doi.org/ 10.1029/97RS02762.

Cameron, A. C., and F. A. G. Windmeijer, 1997: An $R$-squared measure of goodness of fit for some common nonlinear regression models. J. Econom., 77, 329-342, https://doi.org/ 10.1016/S0304-4076(96)01818-0.

Ciesielski, P. E., and Coauthors, 2014: Quality-controlled upper-air sounding dataset for DYNAMO/CINDY/AMIE: Development and corrections. J. Atmos. Oceanic Technol., 31, 741-764, https:// doi.org/10.1175/JTECH-D-13-00165.1.

Fueglistaler, S., A. E. Dessler, T. J. Dunkerton, I. Folkins, Q. Fu, and P. W. Mote, 2009: Tropical tropopause layer. Rev. Geophys., 47, RG1004, https://doi.org/10.1029/2008RG000267.

Gorbunov, M. E., 2002: Radioholographic analysis of radio occultation data in multipath zones. Radio Sci., 37, 1014, https:// doi.org/10.1029/2000RS002577.

_ A. S. Gurvich, and L. Bengtsson, 1996: Advanced algorithms of inversion of GPS/MET satellite data and their application to reconstruction of temperature and humidity. Max Planck Institute for Meteorology Tech. Rep. 211, 40 pp.

, H.-H. Benzon, A. S. Jensen, M. S. Lohmann, and A. S. Nielsen, 2004: Comparative analysis of radio occultation processing approaches based on Fourier integral operators. Radio Sci., 39, RS6004, https://doi.org/10.1029/2003RS002916.

He, W., S.-P. Ho, H. Chen, X. Zhou, D. Hunt, and Y.-H. Kuo, 2009: Assessment of radiosonde temperature measurements in the upper troposphere and lower stratosphere using COSMIC occultation data. Geophys. Res. Lett., 36, L17807, https:// doi.org/10.1029/2009GL038712.

Healy, S. B., and I. D. Culverwell, 2015: A modification to the standard ionospheric correction method used in GPS radio occultation. Atmos. Meas. Tech., 8, 3385-3393, https://doi.org/ 10.5194/amt-8-3385-2015.

Ho, S.-P., L. Peng, and H. Vömel, 2017: Characterization of the long-term radiosonde temperature biases in the upper troposphere and lower stratosphere using COSMIC and MetOp-A/ GRAS data from 2006 to 2014. Atmos. Chem. Phys., 17, 44934511, https://doi.org/10.5194/acp-17-4493-2017.

Jensen, A. S., M. S. Lohmann, H.-H. Benzon, and A. S. Nielsen, 2003: Full spectrum inversion of radio occultation signals. Radio Sci., 38, 1040, https://doi.org/10.1029/2002RS002763. 
,-- , A. S. Nielsen, and H.-H. Benzon, 2004: Geometrical optics phase matching of radio occultation signals. Radio Sci., 39, 3009, https://doi.org/10.1029/2003RS002899.

Kirchengast, G., J. Hafner, and W. Poetzi, 1999: An extension of the CIRA-86 monthly tables including humidity tables and a Fortran 95 global moist air climatology model. University of Graz Institute for Meteorology and Geophysics Tech. Rep. 8 ESA/ESTEC, 18 pp.

Kuo, Y.-H., T. K. Wee, S. Sokolovskiy, C. Rocken, W. Schreiner, and D. Hunt, 2004: Inversion and error estimation of GPS radio occultation data. J. Meteor. Soc. Japan, 82, 507-531, https://doi.org/10.2151/jmsj.2004.507.

, W. S. Schreiner, J. Wang, D. L. Rossiter, and Y. Zhang, 2005: Comparison of GPS radio occultation soundings with radiosondes. Geophys. Res. Lett., 32, L05817, https://doi.org/ 10.1029/2004GL021443.

Kursinski, E. R., G. A. Hajj, J. T. Schofield, R. P. Linfield, and K. R. Hardy, 1997: Observing Earth's atmosphere with radio occultation measurements using the global positioning system. J. Geophys. Res., 102, 23 429-23 465, https://doi.org/10.1029/ 97JD01569.

Laroche, S., and R. Sarrazin, 2013: Impact of radiosonde balloon drift on numerical weather prediction and verification. Wea. Forecasting, 28, 772-782, https://doi.org/10.1175/WAF-D-1200114.1.

Love, P. T., and M. A. Geller, 2012: Research using high (and higher) resolution radiosonde data. Eos, Trans. Amer. Geophys. Union, 93, 337-338, https://doi.org/10.1029/2012EO350001.

Mortensen, M. D., R. P. Linfield, and E. R. Kursinski, 1999: Vertical resolution approaching 100m for GPS occultations of the Earth's atmosphere. Radio Sci., 34, 1475-1484, https://doi.org/10.1029/ 1999RS900093.

Noersomadi, and T. Tsuda, 2017: Comparison of three retrievals of COSMIC GPS radio occultation results in the tropical upper troposphere and lower stratosphere. Earth Planets Space, 69 , 125, https://doi.org/10.1186/s40623-017-0710-7.

Press, W., S. Teulkosky, V. Vetterling, and B. Flannery, 1992: Numerical Recipes in Fortran 77: The Art of Scientific Computing. 2nd ed. Cambridge University Press, 915 pp.

Santer, B. D., and Coauthors, 2003: Contributions of anthropogenic and natural forcing to recent tropopause height changes. Science, 301, 479-483, https://doi.org/10.1126/science.1084123.
Schreiner, W., S. Sokolovskiy, D. Hunt, C. Rocken, and Y.-H. Kuo, 2011: Analysis of GPS radio occultation data from FORMOSAT3/COSMIC and MetOp/GRAS missions at CDAAC. Atmos. Meas. Tech., 4, 2255-2272, https://doi.org/10.5194/amt-4-2255-2011.

Sokolovskiy, S., 2001: Modeling and inverting radio occultation signals in the moist troposphere. Radio Sci., 36, 441-458, https://doi.org/10.1029/1999RS002273.

_ - W. Schreiner, C. Rocken, and D. Hunt, 2009: Optimal noise filtering for the ionospheric correction of GPS radio occultation signals. J. Atmos. Oceanic Technol., 26, 1398-1403, https:// doi.org/10.1175/2009JTECHA1192.1.

— GPS radio occultation data in the neutral atmosphere. GPS Solutions, 18, 405-416, https://doi.org/10.1007/s10291-013-0340-x.

Sun, B., A. Reale, D. J. Seidel, and D. C. Hunt, 2010: Comparing radiosonde and COSMIC atmospheric profile data to quantify differences among radiosonde types and the effects of imperfect collocation on comparison statistics. J. Geophys. Res., 115, D23104, https://doi.org/10.1029/2010JD014457.

Syndergaard, S., 2000: On the ionosphere calibration in GPS radio occultation measurements. Radio Sci., 35, 865-883, https:// doi.org/10.1029/1999RS002199.

Tsuda, T., X. Lin, H. Hayashi, and Noersomadi, 2011: Analysis of vertical wave number spectrum of atmospheric gravity waves in the stratosphere using COSMIC GPS radio occultation data. Atmos. Meas. Tech., 4, 1627-1636, https://doi.org/ 10.5194/amt-4-1627-2011.

Vorobev, V. V., and T. G. Krasilnikova, 1994: Estimation of the accuracy of the refractive index recovery from Doppler shift measurements at frequencies used in the NAVSTAR system. Phys. Atmos. Ocean, 29, 602-609.

Wang, L., and M. J. Alexander, 2010: Global estimates of gravity wave parameters from GPS radio occultation temperature data. J. Geophys. Res., 115, D21122, https://doi.org/10.1029/ 2010JD013860.

Yeh, K. C., and C.-H. Liu, 1982: Radio wave scintillations in the ionosphere. Proc. IEEE, 70, 324-360, https://doi.org/10.1109/ PROC.1982.12313.

Zeng, Z., S. Sokolovskiy, W. Schreiner, D. Hunt, J. Lin, and Y.-H. Kuo, 2016: Ionospheric correction of GPS radio occultation data in the troposphere. Atmos. Meas. Tech., 9, 335-346, https://doi.org/10.5194/amt-9-335-2016. 